\title{
Low-Density Lipoprotein Cholesterol Levels Among Individuals Receiving Statin Therapy: Real-World Evidence from India
}

\author{
Surendra Shamkant Borgharkar ${ }^{1, \text { *, Soma Soumitra Das }}{ }^{2}$ \\ ${ }^{1}$ Sun Pharmaceutical Industries Ltd., Mumbai, India \\ ${ }^{2}$ Covance Scientific Services \& Solutions Pvt. Ltd., Pune, India \\ Email address: \\ sborgharkar@gmail.com (S. S. Borgharkar), soma.das@covance.com (S. S. Das) \\ ${ }^{*}$ Corresponding author
}

To cite this article:

Surendra Shamkant Borgharkar, Soma Soumitra Das. Low-Density Lipoprotein Cholesterol Levels Among Individuals Receiving Statin Therapy: Real-World Evidence from India. American Journal of Health Research. Vol. 9, No. 1, 2021, pp. 16-25.

doi: 10.11648/j.ajhr.20210901.13

Received: January 25, 2021; Accepted: February 20, 2021; Published: March 9, 2021

\begin{abstract}
Despite the established clinical effectiveness of statin therapy, a substantial proportion of patients fail to attain the target low-density lipoprotein cholesterol (LDL-C) levels and remain at risk for cardiovascular events. This study aimed to evaluate the proportion of patients achieving the guideline recommended LDL-C levels in real-world settings after receiving statins for primary and secondary prevention of atherosclerotic cardiovascular disease (ASCVD) in India. The study included a cross-sectional retrospective analysis of medical records from 2281 private healthcare facilities between 2017 and 2018. Overall, 15879 patients aged $20-80$ years irrespective of their ASCVD status were included. Mean $( \pm$ SD) age of patients was $55.96 \pm 10.41$ years; $62.8 \%$ were men, and 44.6\% $(\mathrm{n}=7076)$ had clinical ASCVD. Overall, 96.2\% $(\mathrm{n}=15271)$ patients were receiving statins, $99.3 \%$ in the secondary prevention and $93.6 \%$ in the primary prevention cohort. Most patients were receiving moderate-intensity statins for primary $(89.7 \%, \mathrm{n}=7391)$ and secondary ASCVD prevention $(73.4 \%, \mathrm{n}=5159)$. None of the patients in the secondary prevention cohort achieved the recommended LDL-C level of $<70 \mathrm{mg} / \mathrm{dL}$. Approximately $25.3 \%$ $(\mathrm{n}=2089)$ individuals in the primary prevention and 20.2\% $(\mathrm{n}=1418)$ in the secondary prevention cohort achieved LDL-C $<100$ $\mathrm{mg} / \mathrm{dL}$. Similar proportion $(23.2 \%, \mathrm{n}=3361)$ of patients with LDL-C control $(<100 \mathrm{mg} / \mathrm{dL})$ were found among the high-risk coronary heart disease (CHD) or CHD-equivalent group (including those with diabetes). This large real-world study demonstrated levels of LDL-C that were higher than guideline recommended targets, especially among ASCVD patients, despite receiving statin therapy. The results highlight major gaps in the real-world practice of prescribing statin therapy for both primary and secondary prevention of ASCVD. Concordance to guideline recommended therapy, timely dose titration, use of alternative drugs, and patient adherence can bridge this gap and help achieve optimal control of LDL-C. Further intensification of therapy with addition of non-statins is recommended if LDL-C goals are not achieved among high-risk population.
\end{abstract}

Keywords: Low-density Lipoprotein Cholesterol (LDL-C), Cardiovascular Diseases, Statin Therapy, Real-World Evidence, India

\section{Introduction}

Cardiovascular disease (CVD) is the leading cause of global mortality, accounting for 17.8 million deaths in 2017 $[1,2]$. The high-income countries have witnessed a decline in cardiovascular death rates, but in contrast, a gradual but alarming increase was reported in recent decades from lowerincome countries, including India [2]. CVD is accountable for the highest burden related to mortality in India (2017), with an age-standardized death rate of 282.28 per 100000 , which is higher than the global average of 233.07 [3]. Indians have a predisposition to central obesity and insulin resistance, which enhances the burden of CVD precursors such as dyslipidemia, hypertension, and dysglycemia. Recent studies from India have reported the prevalence of high cholesterol levels among $25 \%$ to $30 \%$ of urban and $15 \%$ to $20 \%$ of rural 
populations [4]. The Indian Council of Medical ResearchIndia Diabetes (ICMR-INDIAB) study demonstrated that Indians tend to have atherogenic dyslipidemia, encompassing high prevalence of low high-density lipoprotein cholesterol levels (HDL-C, 72.3\%), accompanied with elevated levels of triglycerides (29.5\%) and low-density lipoprotein cholesterol (LDL-C, 11.8\%) levels [5].

Evidence from a meta-analysis demonstrated that lower LDL-C levels were significantly associated with reduced rates of major coronary events, both in primary $(1.5 \%$ lower event rate per each $1-\mathrm{mmol} / \mathrm{L}$ lower LDL-C; $\mathrm{p}=0.008)$ and secondary prevention trials $(4.6 \%$ lower event rate per each 1-mmol/L lower LDL-C; $\mathrm{p}<0.001$ ) [6]. Standard treatment guidelines across geographies, including the American College of Cardiology and American Heart Association (ACC/AHA), European Society of Cardiology and European Atherosclerosis Society (EAS/ESC), and National Cholesterol Education Program Adult Treatment Panel III (NCEP ATP), emphasize on reducing LDL-C levels as a key intervention for mitigating risk of cardiovascular events [710]. The guidelines follow a risk-based approach for recommending LDL-C goals. To achieve the LDL-C targets, the guidelines suggest a combination of lifestyle modification and lipid-lowering therapies. Statin therapy is the mainstay for LDL-C reduction; with one year of statin use, each 1 $\mathrm{mmol} / \mathrm{L}(38.6 \mathrm{mg} / \mathrm{dL})$ of reduction in LDL-C leads to a $20 \%$ to $25 \%$ relative reduction of global CVD risk and a $20 \%$ decrease in coronary mortality $[11,12]$.

Despite the established clinical effectiveness of statin therapy, considerable individuals undergoing treatment are unable to attain the target levels of LDL-C in the real-world, thus rendering them at risk of cardiovascular events. The prospective Centralized Pan-European survey on tHE Undertreatment of hypercholeSterolemia (CEPHEUS) Pan-Asian study, reported LDL-C goal attainment in $51.2 \%$ of primary and $48.7 \%$ of secondary prevention patients [13]. The Dyslipidemia International Study (DYSIS) II reported that $48.3 \%$ and $37.5 \%$ of patients with coronary heart disease (CHD) and acute coronary syndrome from India had LDL-C $<70 \mathrm{mg} / \mathrm{dL}$ [14]. However, the study was conducted in a large single-center Multispeciality tertiary care hospital in India including 1049 patients, wherein the treatment pattern might be different from routine primary care practice. Largescale real-world studies determining the LDL-C levels among individuals treated with lipid-lowering therapies are scarce in the Indian population. This pan-India study was conducted with an aim to evaluate the LDL-C control among individuals receiving statin therapy for the primary and secondary prevention of atherosclerotic cardiovascular disease (ASCVD) in routine clinical practice.

\section{Research Design and Methodology}

\subsection{Study Design}

This cross-sectional study included 2281 private healthcare centres across India between 2017 and 2018. The inclusion of healthcare facilities was uniformly distributed across the different regions of the country (Southern India: 40\%, Western India: 22\%, Eastern India: 18\%, Northern India: 14\%, Central India: 4\% and North-Eastern India: 2\%). Healthcare providers, including physicians and cardiologists, retrospectively transcribed protocol-defined data on the Lipid and Risk Markers in Indian Population (LIPIMAP) data collection form based on the available medical records. Individuals of either sex, aged 20 to 80 years, irrespective of their ASCVD status were included. Data of individuals with missing or erroneous values were excluded. The study was approved by the local ethics committee and was granted a waiver for patient consent as it involved only retrospective chart review without direct patient involvement.

\subsection{Study Outcomes}

The primary outcome was to determine the proportion of individuals receiving statin therapy for the primary and secondary prevention of ASCVD achieving guideline recommended levels of LDL-C. The operational definitions for statin therapy, glycemic control, body mass index (BMI), blood pressure, and dyslipidemia are described in Table 1.

\subsection{Data Collection and Statistical Analysis}

Data collection comprised of demographic and clinical details such as diabetes or ASCVD history and tobacco use. In addition, anthropometric variables, alongside treatment history with antihypertensive, and statin therapy were recorded. The latest available laboratory results for glycated hemoglobin (HbA1c), total cholesterol (TC), LDL-C, HDL-C, and triglycerides were recorded. Continuous variables are presented as means with standard deviations (SD) and categorical variables are given as absolute values and percentages. Descriptive analyses and cross-tabulations were performed to estimate the LDL-C levels for the different risk groups. Statistical analyses were performed using SAS version 9.4 and $p<0.05$ was considered statistically significant.

\section{Results}

\subsection{Demographic and Clinical Profile}

A total of 15879 records were found eligible for inclusion in the study between 2017 and 2018. Table 2 summarizes the demographic and clinical characteristics of the study population. The mean $( \pm \mathrm{SD})$ age of study participants was $55.96 \pm 10.41$ years; majority of individuals $(91.4 \% \mathrm{n}=14509)$ were in the age group of 40 to 75 years. The study population had a male predominance $(62.8 \% \mathrm{n}=9977)$, and $31.9 \%$ $(n=5071)$ were tobacco users at the time of data collection. The mean BMI of the study population was $26.87 \pm 3.41 \mathrm{~kg} / \mathrm{m}^{2}$ and more than half $(58.7 \%, \mathrm{n}=9325)$ were obese. Overall, $44.6 \%(\mathrm{n}=7076)$ patients had a history of established ASCVD and $91.1 \%(\mathrm{n}=14464)$ of individuals had diabetes mellitus. About $77.1 \% \quad(\mathrm{n}=12235)$ patients were receiving antihypertensive medications. Patients with prior ASCVD had a higher history of tobacco use $(62.5 \%, n=3168)$ and 
hypertension $(56.8 \%, \mathrm{n}=3377)$ compared with individuals with prior history of ASCVD. However, obesity (54.1\%, $\mathrm{n}=5036)$, prehypertension $(62.3 \%, \mathrm{n}=5947)$, and diabetes $(54.6 \%, \mathrm{n}=7894)$ were substantially high among individuals without ASCVD. Fifty-four percent $(n=6603)$ of individuals in the ASCVD group were receiving antihypertensive medications (Table 1). The mean TC level among the study population was $196.00 \pm 25.91 \mathrm{mg} / \mathrm{dL}$, and $55.3 \%(\mathrm{n}=8778)$ had TC $<200 \mathrm{mg} / \mathrm{dL}$. The mean LDL-C level in the overall population was $122.06 \pm 29.41 \mathrm{mg} / \mathrm{dL}$, only $23.2 \%(\mathrm{n}=3681)$ had LDL-C level $<100 \mathrm{mg} / \mathrm{dL}$, while $2.5 \%(\mathrm{n}=404)$ had a LDL-C level of $\geq 190 \mathrm{mg} / \mathrm{dL}$. The mean triglyceride level was $177.97 \pm 57.47 \mathrm{mg} / \mathrm{dL}$, and only one-third $(31.3 \%)$ of individuals $(\mathrm{n}=4976)$ had triglyceride level $<150 \mathrm{mg} / \mathrm{dL}$.

Table 1. Operational definitions for categorizing the study population.

\begin{tabular}{|c|c|}
\hline Guideline & Categories \\
\hline $\begin{array}{l}\text { Statin therapy } \\
\text { (2018 American College of Cardiology (ACC) and American } \\
\text { Heart Association (AHA) guideline) [7] }\end{array}$ & $\begin{array}{l}\text { 1. High-intensity statin (atorvastatin } 40 \text { and } 80 \mathrm{mg} \text {, rosuvastatin } 20 \text { and } 40 \mathrm{mg} \text { ) } \\
\text { 2. Moderate-intensity statin (atorvastatin } 10-20 \mathrm{mg} \text {, rosuvastatin } 5 \text { to } 10 \mathrm{mg} \text {, simvastatin } \\
20-40 \mathrm{mg} \text { and pitavastatin } 2-4 \mathrm{mg} \text { ) } \\
\text { 3. Low-intensity statin (simvastatin } 10 \mathrm{mg} \text { ) }\end{array}$ \\
\hline Glycemic control (American Diabetes Association 2018) [33] & $\begin{array}{l}\text { 1. Controlled }(\mathrm{HbA} 1 \mathrm{c}<7 \%) \\
\text { 2. Uncontrolled }(\mathrm{HbA} 1 \mathrm{c} \geq 7 \%)\end{array}$ \\
\hline $\begin{array}{l}\text { Body mass index (BMI) (Consensus Statement for Diagnosis } \\
\text { of Obesity, Abdominal Obesity and the Metabolic Syndrome } \\
\text { for Asian Indians and Recommendations for Physical } \\
\text { Activity, Medical and Surgical Management) [34] }\end{array}$ & $\begin{array}{l}\text { 1. Normal }\left(18-22.9 \mathrm{~kg} / \mathrm{m}^{2}\right) \\
\text { 2. Overweight }\left(2324.9 \mathrm{~kg} / \mathrm{m}^{2}\right) \\
\text { 3. Obese }\left(\geq 25 \mathrm{~kg} / \mathrm{m}^{2}\right)\end{array}$ \\
\hline $\begin{array}{l}\text { Blood pressure (BP in mmHg) (Seventh Report of the Joint } \\
\text { National Committee on Prevention, Detection, Evaluation, } \\
\text { and Treatment of High Blood Pressure) [35] }\end{array}$ & $\begin{array}{l}\text { 1. Prehypertension }(\mathrm{SBP}]=120-139 \text { or diastolic } \mathrm{BP}[\mathrm{DBP}]=80-89) \\
\text { 2. Stage } 1 \text { hypertension }(\mathrm{SBP}=140-159 \text { or } \mathrm{DBP}=90-99) \\
\text { 3. Stage } 2 \text { hypertension }(\mathrm{SBP} \geq 160 \text { or } \mathrm{DBP} \geq 100)\end{array}$ \\
\hline $\begin{array}{l}\text { Dyslipidemia Updated National Cholesterol Education } \\
\text { Program Adult Treatment Panel [NCEP ATP III] guideline } \\
{[10]}\end{array}$ & $\begin{array}{l}\text { 1. Total cholesterol (TC) Desirable }(<200 \mathrm{mg} / \mathrm{dL}) \text {, borderline-high }(200-239 \mathrm{mg} / \mathrm{dL}) \text { and } \\
\text { high }(\geq 240 \mathrm{mg} / \mathrm{dL}) \\
\text { 2. HDL-C: } \mathrm{men} \text { (low }(<40 \mathrm{mg} / \mathrm{dL}) \text {, high }(\geq 40 \mathrm{mg} / \mathrm{dL}) \text { and women, low }(<50 \mathrm{mg} / \mathrm{dL}) \text {, } \\
\text { high }(\geq 50 \mathrm{mg} / \mathrm{dL}) \\
\text { 3. Triglycerides: normal }(<150 \mathrm{mg} / \mathrm{dL}) \text {, borderline-high }(150-199 \mathrm{mg} / \mathrm{dL}) \text {, and high } \\
(200-499 \mathrm{mg} / \mathrm{dL}) \\
\text { 4. }{ }^{*} \text { LDL-C goals; } 0 \text { - } 1 \text { risk factor }(<160 \mathrm{mg} / \mathrm{dL}), 2+\text { risk factors }(<100 \mathrm{mg} / \mathrm{dL}) \text {, and CHD } \\
\text { or CHD risk equivalents }{ }^{\dagger}(<100 \mathrm{mg} / \mathrm{dL}) \text { and }(<70 \mathrm{mg} / \mathrm{dL})\end{array}$ \\
\hline
\end{tabular}

*The LDL-C goals were classified according to the presence of risk factors (tobacco use, hypertension [BP $>140 / 90$ mmHg or on antihypertensive medication]), low HDL cholesterol $(<40 \mathrm{mg} / \mathrm{dL})$, and age (men $>45$ years; women $>55$ years). Data on chronic kidney disease and family history of premature CHD were not available.

${ }^{\dagger} \mathrm{CHD}$ includes history of myocardial infarction, unstable angina, stable angina, coronary artery procedures (angioplasty or bypass surgery), or evidence of clinically significant myocardial ischemia. CHD risk equivalents include clinical manifestations of non-coronary forms of atherosclerotic, diabetes, and $2+$ risk factors with 10-year risk for hard CHD $>20 \%$.

BMI, body mass index; BP, blood pressure; HbA1c, glycated hemoglobin; SBP, systolic blood pressure; DBP, blood pressure; TC; total cholesterol; HDL-C, high-density lipoprotein cholesterol; LDL-C, low-density Lipoprotein Cholesterol

\subsection{Statin Therapy}

Overall, 96.2\% $(n=15271)$ of individuals in the cohort were treated with statin therapy on the day of data collection. Almost all (99.3\%) ( $\mathrm{n}=7028)$ patients with ASCVD and 93.6\% $(\mathrm{n}=8243)$ without ASCVD were treated with statin therapy. The study population primarily received atorvastatin $(69.0 \%, \mathrm{n}=10543)$ and rosuvastatin $(30.9 \%, \mathrm{n}=4713)$; fewer patients were prescribed pitavastatin $(n=9)$ or simvastatin $(n=6)$. Of the patients in the ASCVD group eligible for high-intensity statins, only $26.6 \%$ $(\mathrm{n}=1869)$ adequately received high-intensity statin therapy: atorvastatin 40 to $80 \mathrm{mg}(12.7 \% ; \mathrm{n}=890)$ and rosuvastatin 20 to 40 $\mathrm{mg}(13.9 \% ; n=979)$. Most patients with ASCVD remained undertreated with moderate-intensity statins: atorvastatin 10 to $20 \mathrm{mg}$ $(57.2 \% ; n=4022)$ and rosuvastatin 5 to $10 \mathrm{mg}(16 \% ; n=1127)$. Among non-ASCVD individuals, majority received moderateintensity statins: atorvastatin 10 to $20 \mathrm{mg}(65.5 \%, \mathrm{n}=5396)$ and rosuvastatin 5 to $10 \mathrm{mg}(24.1 \%, \mathrm{n}=1990)$ (Figure 1).

\subsection{LDL-C level: Primary and Secondary Prevention Cohort}

The mean LDL-C levels were 126.47 \pm 31.02 and $118.49 \pm 27.53$ among patients with ASCVD and without ASCVD, respectively. None of the patients in the ASCVD group had LDL-C levels $<70 \mathrm{mg}$ per the recommended guidelines. Of the patients with ASCVD receiving statin therapy $(n=7028)$, only $20.2 \%(n=1418)$ had LDL-C $<100$ $\mathrm{mg} / \mathrm{dL}$ (Figure 2). Most of the ASCVD patients with LDL-C levels $\geq 100 \mathrm{mg} / \mathrm{dL}(\mathrm{n}=5610)$ were treated with moderateintensity statin therapy $(74.9 \% ; n=4200)$, while only $25.1 \%$ $(n=1409)$ patients received high-intensity statins. Similarly, among individuals with non-ASCVD, 25.3\% ( $\mathrm{n}=2089)$ achieved LDL-C $<100 \mathrm{mg} / \mathrm{dL}$. Of the non-ASCVD individuals with LDL-C $\geq 100 \mathrm{mg} / \mathrm{dL}$ ( $\mathrm{n}=6154)$, majority 
(89.2\%; $n=6154)$ received moderate-intensity statin therapy. $\quad(n=3969)$ and $78.4 \% \quad(n=1641)$ of males and females, Gender distribution of the study population revealed that $80.4 \%$ respectively, had LDL-C $\geq 100 \mathrm{mg} / \mathrm{dL}$ in the ASCVD group.

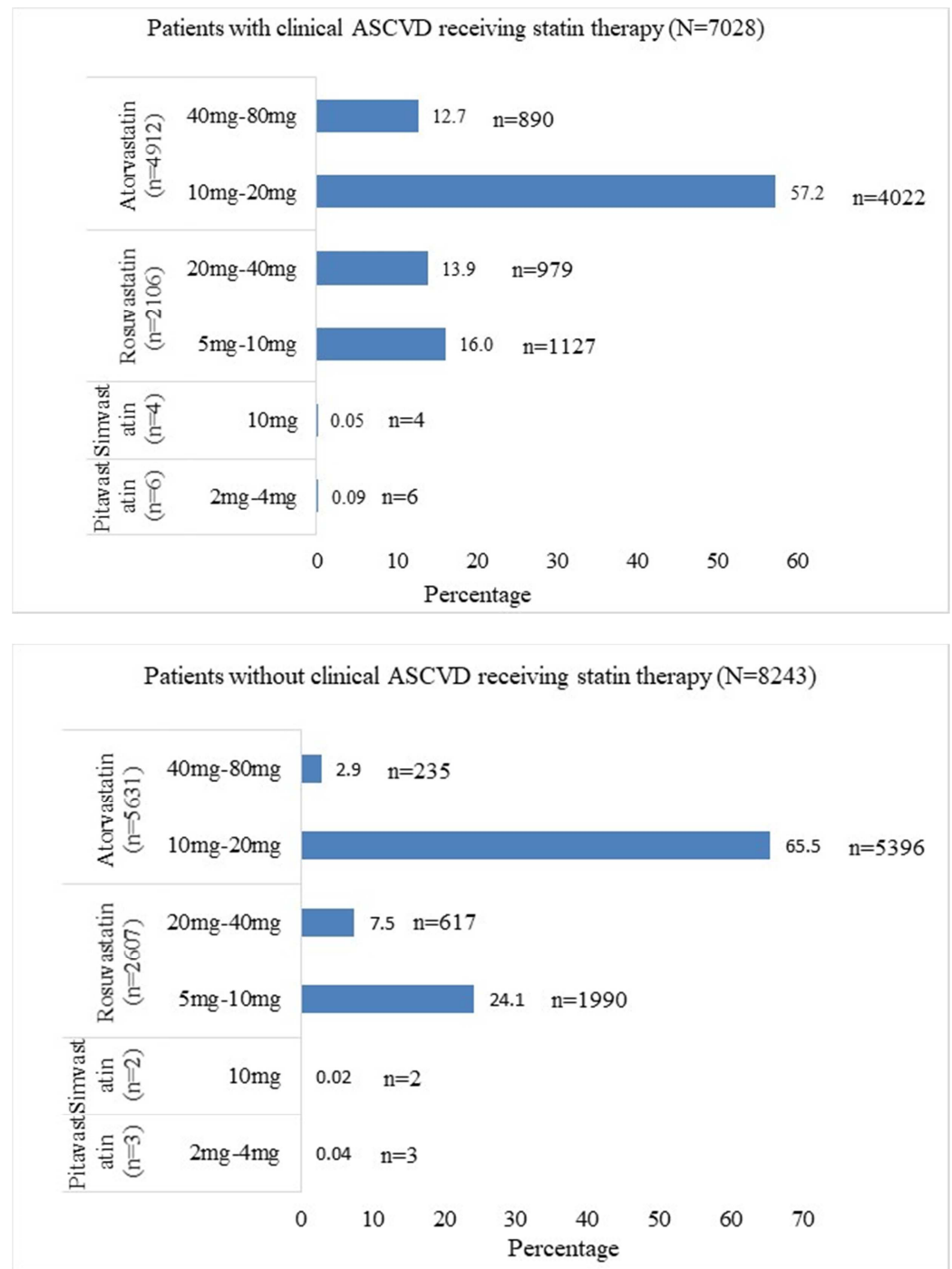

Figure 1. Distribution of statin therapy among the study population for primary and secondary prevention of ASCVD.

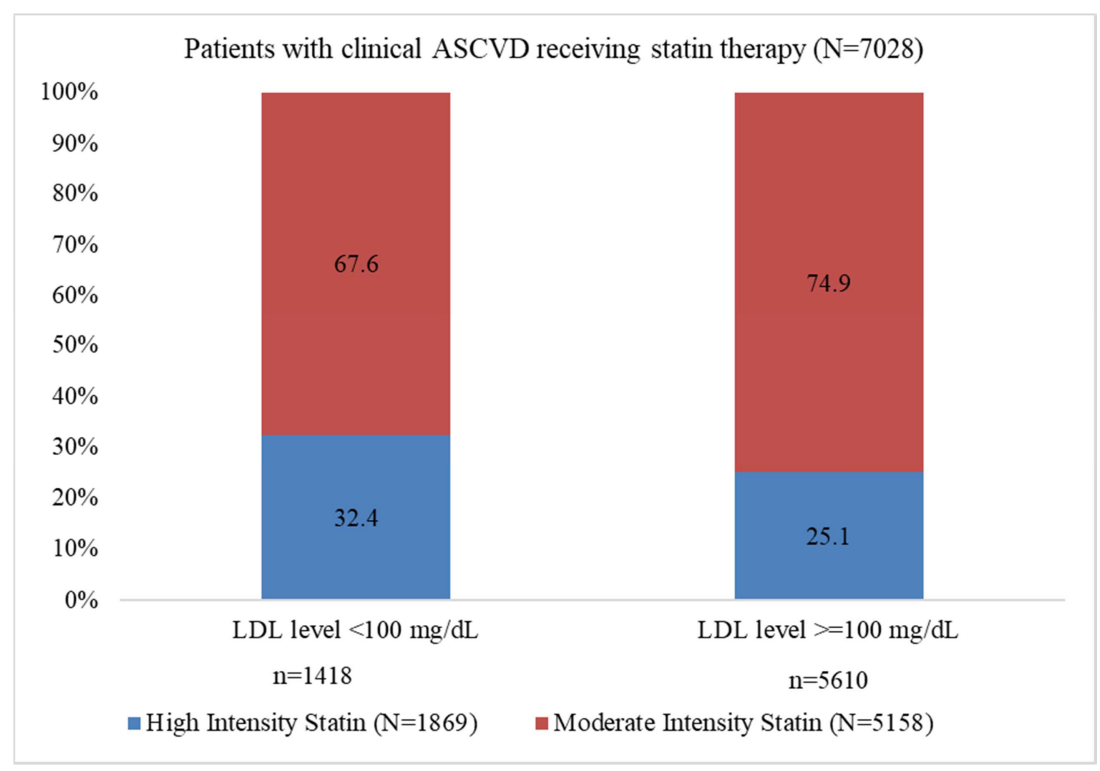




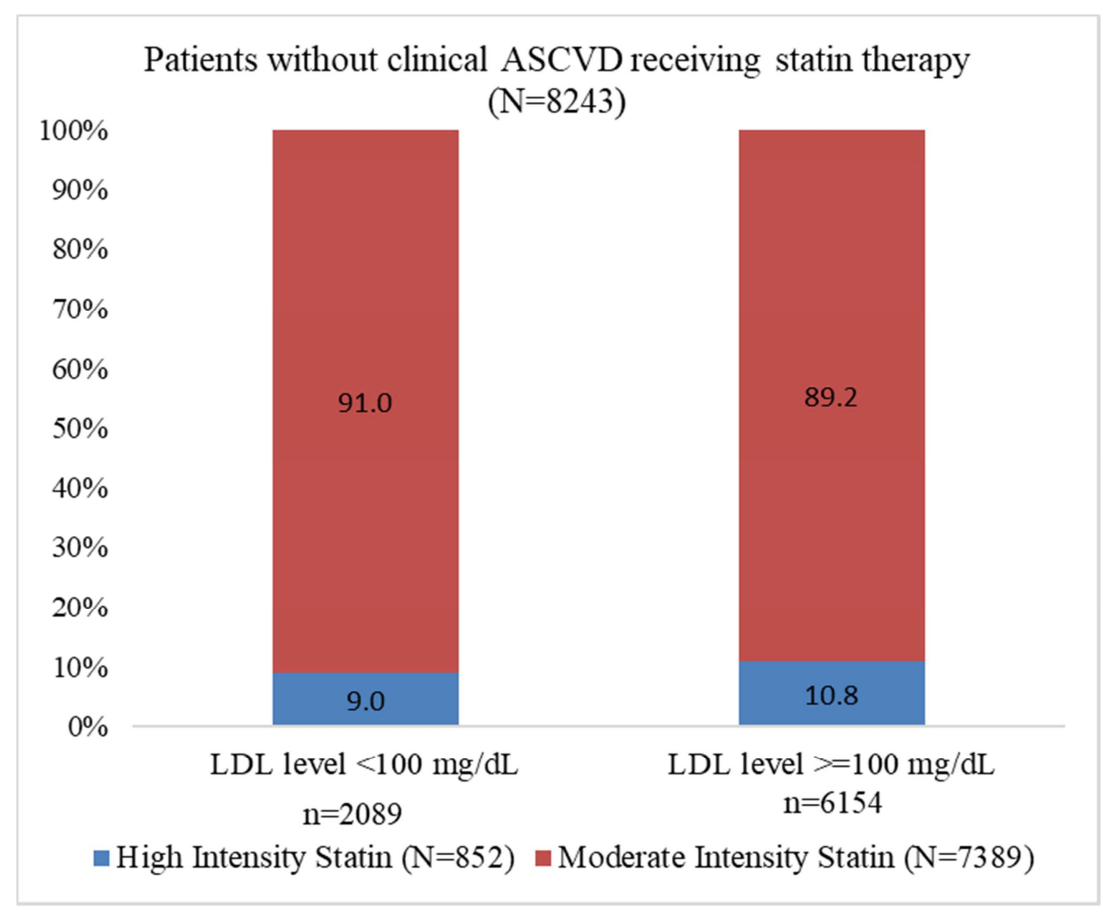

Figure 2. $L D L-C$ level of patients receiving statin therapy for primary and secondary prevention of ASCVD.

* None of the patients achieved the recommended LDL-C target of $<70 \mathrm{mg} / \mathrm{dL}$

${ }^{\dagger}$ Overall $(\mathrm{n}=3)$ patients received low-intensity statins

LDL-C, low-density Lipoprotein Cholesterol; ASCVD, atherosclerotic cardiovascular diseases

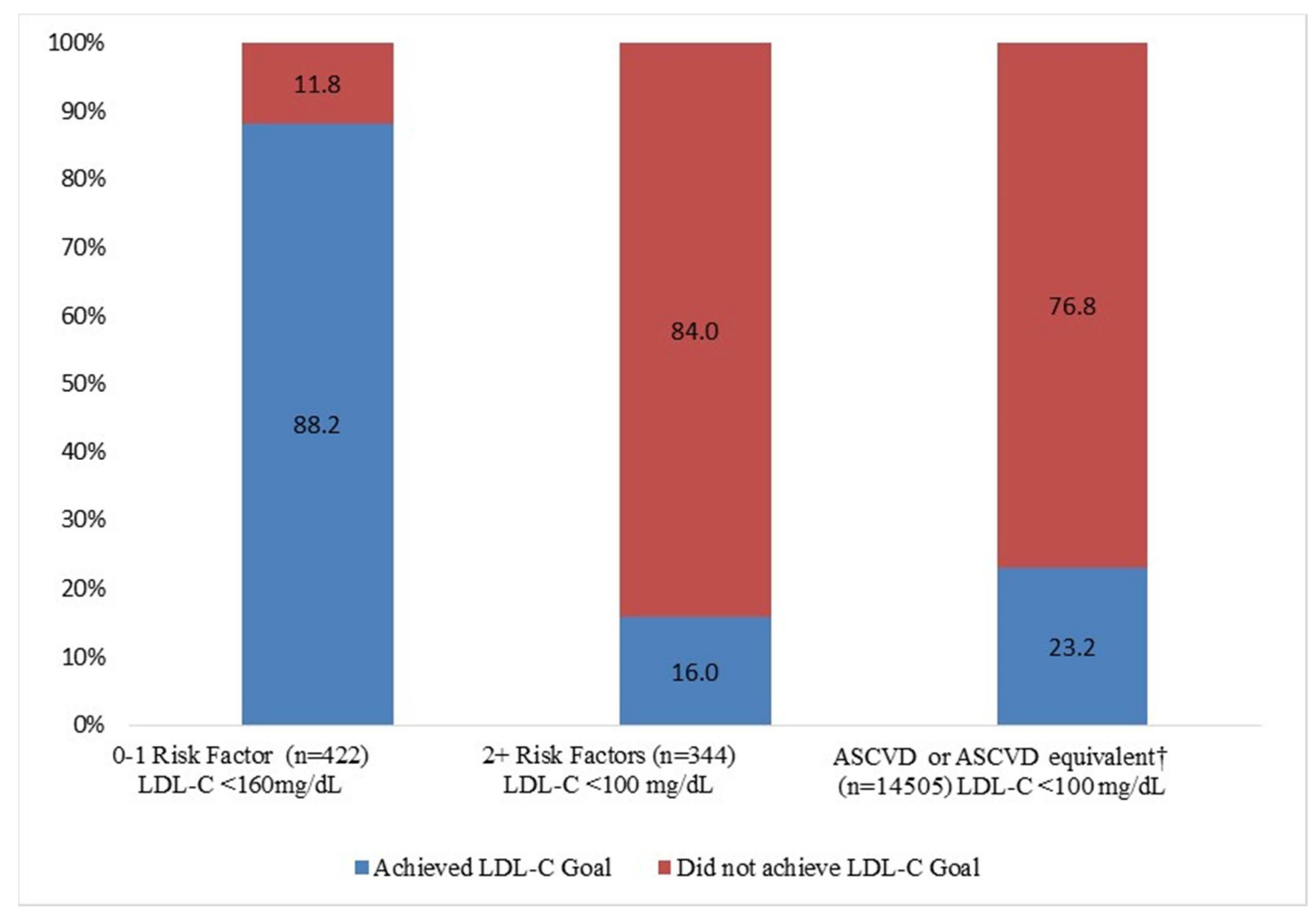

Figure 3. $L D L-C$ level of patients receiving statin therapy segregated by risk groups based on the updated NCEP ATP 3 guideline.

None of the patients achieved the recommended LDL-C target of $<70 \mathrm{mg} / \mathrm{dL}$

*Risk factors: Tobacco use, hypertension (blood pressure $>140 / 90 \mathrm{mmHg}$ or on antihypertensive medication), low HDL cholesterol ( $<40 \mathrm{mg} / \mathrm{dL}$ ), and age (men $>45$ years; women $>55$ years). Data on chronic kidney disease, and family history was not available

${ }^{\dagger}$ ASCVD-equivalent includes patients with diabetes based on the NCEP ATP guidelines.

LDL-C, low-density Lipoprotein Cholesterol; ASCVD, atherosclerotic cardiovascular diseases 
Table 2. Demographic and clinical characteristics of the study population.

\begin{tabular}{|c|c|c|c|c|c|c|}
\hline & \multicolumn{2}{|l|}{ Overall } & \multicolumn{2}{|c|}{ Clinical ASCVD } & \multicolumn{2}{|c|}{ No clinical ASCVD } \\
\hline & $\mathbf{N}$ & $\%$ & n & $\%$ & n & $\%$ \\
\hline Total & 15,879 & & 7,076 & & 8,803 & \\
\hline \multicolumn{7}{|l|}{ Age $($ Mean \pm SD $55.96 \pm 10.41)$} \\
\hline$<40$ years & 987 & 6.2 & 221 & 3.1 & 766 & 8.7 \\
\hline $45-75$ years & 14,509 & 91.4 & 6,614 & 93.5 & 7,895 & 89.7 \\
\hline$>75$ years & 383 & 2.4 & 241 & 3.4 & 142 & 1.6 \\
\hline \multicolumn{7}{|l|}{ Gender } \\
\hline Male & 9,977 & 62.8 & 4,963 & 70.1 & 5,014 & 57.0 \\
\hline Female & 5,902 & 37.2 & 2,113 & 29.9 & 3,789 & 43.0 \\
\hline Tobacco use & 5071 & 31.9 & 3,168 & 44.8 & 1,903 & 21.6 \\
\hline \multicolumn{7}{|l|}{ Body mass index $\left(\mathrm{kg} / \mathrm{m}^{2}\right)($ Mean \pm SD) $26.87 \pm 3.41$} \\
\hline Normal $\left(18-22.9 \mathrm{~kg} / \mathrm{m}^{2}\right)$ & 1750 & 11.0 & 764 & 10.8 & 986 & 11.2 \\
\hline Overweight $\left(23-24.9 \mathrm{~kg} / \mathrm{m}^{2}\right)$ & 2,312 & 14.6 & 1028 & 14.5 & 1,284 & 14.6 \\
\hline Obesity $(\geq 25)$ & 9,325 & 58.7 & 4,289 & 60.6 & 5,036 & 57.2 \\
\hline \multicolumn{7}{|l|}{ Blood pressure } \\
\hline Normal $(\mathrm{SBP}=<120$ or $\mathrm{DBP}=<80) \dagger$ & 386 & 2.4 & 98 & 1.4 & 288 & 3.3 \\
\hline Prehypertension $(\mathrm{SBP}=120-139$ or $\mathrm{DBP}=80-89)$ & 9,548 & 60.1 & 3,601 & 50.9 & 5947 & 67.6 \\
\hline Stage 1 Hypertension $(\mathrm{SBP}=140-159$ or $\mathrm{DBP}=90-99)$ & 5267 & 33.2 & 2,967 & 41.9 & 2,300 & 26.1 \\
\hline Stage 2 Hypertension ( $\mathrm{SBP} \geq 160$ or $\mathrm{DBP} \geq 100)$ & 678 & 4.3 & 410 & 5.8 & 268 & 3.0 \\
\hline *Receiving antihypertensive treatment & 12,235 & 77.1 & 6,603 & 93.3 & 5,632 & 63.9 \\
\hline Diagnosed as Diabetic & 14,464 & 91.1 & 6,570 & 92.9 & 7,894 & 89.7 \\
\hline Receiving statin therapy & 15,271 & 96.2 & 7,028 & 99.3 & 8,243 & 93.6 \\
\hline \multicolumn{7}{|l|}{ Total Cholesterol (Mean \pm SD) 196.00 \pm 25.91} \\
\hline Desirable $(<200 \mathrm{mg} / \mathrm{dL})$ & 8,778 & 55.3 & 3,558 & 50.3 & 5,220 & 59.3 \\
\hline Borderline-high $(200-239 \mathrm{mg} / \mathrm{dL})$ & 5,902 & 37.2 & 2,873 & 40.6 & 3,029 & 34.4 \\
\hline $\operatorname{High}(\geq 240 \mathrm{mg} / \mathrm{dL})$ & 1,199 & 7.6 & 645 & 9.1 & 554 & 6.3 \\
\hline \multicolumn{7}{|l|}{ High-density Lipoprotein (HDL) (Mean \pm SD) $42.44 \pm 7.63$} \\
\hline Low $(<40 \mathrm{mg} / \mathrm{dL})-$ Male & 3,716 & 23.4 & 1,901 & 26.9 & 1,815 & 20.6 \\
\hline$(\geq 40 \mathrm{mg} / \mathrm{dL})-$ Male & 6,261 & 39.4 & 3,062 & 43.3 & 3,199 & 36.3 \\
\hline Low $(<50 \mathrm{mg} / \mathrm{dL})-$ Female & 4,891 & 30.8 & 1,780 & 25.2 & 3,111 & 35.3 \\
\hline$(\geq 50 \mathrm{mg} / \mathrm{dL})-$ Female & 1,011 & 6.4 & 333 & 4.7 & 678 & 7.7 \\
\hline \multicolumn{7}{|l|}{ Triglyceride (Mean \pm SD) $177.97 \pm 57.47$} \\
\hline $\operatorname{Normal}(<150 \mathrm{mg} / \mathrm{dL})$ & 4,976 & 31.3 & 1,928 & 27.3 & 3,048 & 34.6 \\
\hline Borderline-high (150-199 mg/dL) & 6,333 & 39.9 & 2,834 & 40.1 & 3,499 & 39.8 \\
\hline $\operatorname{High}(200-500 \mathrm{mg} / \mathrm{dL})$ & 4,567 & 28.8 & 2314 & 32.7 & 2,253 & 25.6 \\
\hline Very high $(\geq 500)$ & 3 & 0.0 & 0 & 0.0 & 3 & 0.0 \\
\hline
\end{tabular}

Results are presented as column percentages. The percentages may not total because of presence of missing values

*The percentage of individuals receiving antihypertensive has been calculated from the total population

${ }^{\dagger} \mathrm{SBP}=$ Systolic blood pressure, $\mathrm{DBP}=$ Diastolic blood pressure

\subsection{Individuals Achieving LDL-C Goal in the Different Risk Groups (Per Updated NCEP ATP Guidelines)}

In our study, the patients with established ASCVD included those with CHD and non-coronary forms of atherosclerotic disease, whereas ASCVD-equivalent group included high-risk individuals with diabetes (based on the NCEP ATP 3 guidelines). Among the patients in the ASCVD or ASCVD-equivalent group ( $\mathrm{N}=14505), 23.2 \% \quad(\mathrm{n}=3361)$ achieved the LDL-C threshold of $<100 \mathrm{mg} / \mathrm{dL}$ (Figure 3). Of the patients in ASCVD or ASCVD-equivalent group with LDL-C $\geq 100 \mathrm{mg} \quad(\mathrm{N}=11144), 82.3 \% \quad(\mathrm{n}=9167)$ received moderate-intensity statins. Among the non-ASCVD individuals with two or more risk factors $(\mathrm{n}=344), 16.0 \%$ $(\mathrm{n}=55)$ had LDL-C $<100 \mathrm{mg} / \mathrm{dL}$, while among those with 0 to 1 risk factor $(\mathrm{N}=422), 88.2 \%(\mathrm{n}=372)$ had LDL-C $<160$ $\mathrm{mg} / \mathrm{dL}$.

\subsection{LDL-C Goal Achievement in Individuals with Type 2 Diabetes Mellitus (T2DM)}

Among the individuals with T2DM ( $\mathrm{N}=14464)$, less than one-fourth (23.5\%) achieved the LDL-C goal $<100$ $\mathrm{mg} / \mathrm{dL}$ and amongst this population $17.5 \%$ and $78.4 \%$ were receiving high-intensity and moderate-intensity statins, respectively (Table 3 ). In very-high risk patients having comorbid ASCVD and T2DM, the majority had LDL-C level $\geq 100 \mathrm{mg} / \mathrm{dL}(79.9 \%)$ and amongst this population, $74 \%$ were receiving moderate-intensity, while $25.5 \%$ were receiving high-intensity statins. In patients with T2DM alone, $73.8 \%$ had LDL-C level $\geq 100$ $\mathrm{mg} / \mathrm{dL}$ with majority $(85.3 \%)$ receiving moderateintensity statins; however, $4.9 \%$ were not receiving any 
statin therapy.

\subsection{LDL-C goal and Duration of Statin Therapy}

Among the individuals receiving statin therapy $(\mathrm{N}=15,271), 26.0 \%(\mathrm{n}=3,972)$ were treated with statins for the previous 2 to 5 years, and $17.7 \%(n=2,699)$ individuals had been receiving statins for more than 5 years. Among the high-risk patients in the ASCVD/ASCVD-equivalent group, the proportion of patients who achieved LDL-C level $<100 \mathrm{mg} / \mathrm{dL}$ statistically increased with the duration of statin therapy: past 6 to 12 months $(6.1 \% ; n=507)$, past 1 to 2 years $(28.1 \%$; $=885)$, past 2 to 5 years $(30.6 \%$; $\mathrm{n}=962)$, and more than 5 years $(25.2 \% ; \mathrm{n}=794)(\mathrm{p}<0.01)$ (Table 4).

Table 3. LDL-C level of patients with type 2 diabetes mellitus in the study population.

\begin{tabular}{|c|c|c|c|c|c|c|}
\hline \multirow[b]{3}{*}{ LDL-C (mg/dL) } & \multicolumn{4}{|c|}{ Total patients with T2DM $(A+B)$} & \multicolumn{2}{|c|}{ Patients with ASCVD and T2DM (A) } \\
\hline & HIS $(\mathrm{N}=\mathbf{2 4 9 8})$ & $\operatorname{MIS}(\mathrm{N}=11511)$ & NS $(N=452)$ & Total $(N=14464)$ & HIS $(N=1765)$ & $\operatorname{MIS}(\mathrm{N}=4769)$ \\
\hline & n (\%) & n $(\%)$ & n $(\%)$ & n $(\%)$ & n $(\%)$ & n $(\%)$ \\
\hline$<100$ & $595(17.5)$ & $2659(78.4)$ & $138(4.1)$ & $3392(23.5)$ & $427(32.3)$ & $884(67)$ \\
\hline
\end{tabular}

Table 3. Continued.

\begin{tabular}{|c|c|c|c|c|c|c|}
\hline \multirow[b]{2}{*}{ LDL-C (mg/dL) } & \multicolumn{2}{|c|}{ Patients with ASCVD and T2DM (A) } & \multicolumn{4}{|c|}{ Patients with T2DM alone (B) } \\
\hline & $\begin{array}{l}\text { NS }(\mathrm{N}=35) \\
\text { n }(\%)\end{array}$ & $\begin{array}{l}\text { Total }(\mathrm{N}=6570) \\
\text { n }(\%)\end{array}$ & $\begin{array}{l}\text { HIS }(N=733) \\
n(\%)\end{array}$ & $\begin{array}{l}\text { MIS }(N=6742) \\
\text { n }(\%)\end{array}$ & $\begin{array}{l}\text { NS }(N=417) \\
\text { n }(\%)\end{array}$ & $\begin{array}{l}\text { Total }(\mathrm{N}=7894) \\
\text { n }(\%)\end{array}$ \\
\hline$<100$ & $9(0.7)$ & $1320(20.1)$ & $168(8.1)$ & $1775(85.7)$ & $129(6.2)$ & $2072(26.2)$ \\
\hline
\end{tabular}

T2DM, Type 2 diabetes mellitus; LDL-C, Low-density Lipoprotein Cholesterol; ASCVD, atherosclerotic cardiovascular diseases; HIS, High-Intensity Statins; MIS, Moderate-Intensity Statins; NS, Not on statins

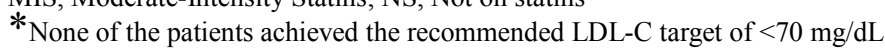

$\dagger$ Overall $(\mathrm{n}=3)$ patients received low-intensity statins

Table 4. LDL-C level based on the statin duration for the ASCVD or ASCVD-equivalent risk group.

\begin{tabular}{|c|c|c|c|c|c|c|c|c|c|}
\hline & \multicolumn{2}{|c|}{ 6-12 months } & \multicolumn{2}{|c|}{ Past 1-2 years } & \multicolumn{2}{|c|}{ Past 2-5 years } & \multicolumn{2}{|c|}{ More than 5 years } & \multirow[t]{2}{*}{ p value } \\
\hline & $\mathbf{N}$ & $\%$ & $\mathbf{N}$ & $\%$ & $\mathbf{N}$ & $\%$ & $\mathbf{N}$ & $\%$ & \\
\hline & 2,636 & & 4,504 & & 3,832 & & 2,670 & & \\
\hline $\mathrm{LDL}<100 \mathrm{mg} / \mathrm{dL}$ & 507 & 16.1 & 885 & 28.1 & 962 & 30.6 & 794 & 25.2 & \\
\hline $\mathrm{LDL} \geq 100 \mathrm{mg} / \mathrm{dL}$ & 2,129 & 20.29 & 3,619 & 34.5 & 2,870 & 27.4 & 1,876 & 17.9 & $<0.0001$ \\
\hline
\end{tabular}

*ASCVD-equivalent includes patients with diabetes according to the NCEP ATP guideline

LDL-C, low-density Lipoprotein Cholesterol; ASCVD, atherosclerotic cardiovascular diseases

\section{Discussion}

This pan-India study evaluated the LDL-C control among a large, real-world cohort of individuals from routine clinical practice. Most individuals (79\%) received moderate-intensity statins for primary and secondary prevention of ASCVD. None of the patients in the ASCVD group had LDL-C levels $<70 \mathrm{mg}$ per the recommended guidelines. Only one-fifth of ASCVD patients and one-fourth of non-ASCVD individuals achieved the LDL-C level $<100 \mathrm{mg} / \mathrm{dL}$. Similarly, only 1 in 5 patients with comorbid ASCVD and diabetes achieved LDL$\mathrm{C}$ thresholds of $<100 \mathrm{mg} / \mathrm{dL}$.

The findings from our study are consistent with earlier studies on statin utilization among patients with high CVD risk. A real-world study from Germany reported a comparatively lower proportion of LDL-C goal achievement (albeit a higher percentage than our study), 30\% patients in ASCVD group and $23.6 \%$ in the non-ASCVD group achieved LDL-C goals $<100 \mathrm{mg} / \mathrm{dL}$. [15]. The DemographIc Assessment and EValuation of DEgree of Lipid Control in High-Risk Indian DySlipidemia PatiEnts (DIVERSE) study, across 483 sites in India, reported that only $7.7 \%$ patients achieved LDL-C levels $<70 \mathrm{mg} / \mathrm{dL}$ and $18.5 \%$ achieved
LDL-C levels between 70 to $100 \mathrm{mg} / \mathrm{dL}$ [16]. The Dyslipidemia International Study (DYSIS) II, a multinational study (including India), showed that among patients with CHD, $74.1 \%$ and $32.6 \%$ achieved LDL-C levels $<100 \mathrm{mg} / \mathrm{dL}$ and $<70 \mathrm{mg} / \mathrm{dL}$, respectively [14]. However, majority (91.7\%) of the patients in the DYSIS study were using lipid-lowering therapy, including non-statin medications. The SURF study (SUrvey of Risk Factors) conducted in 11 countries reported a higher usage of statins in Europe (86.8\%) as compared with Asia $(51 \%, \mathrm{p}<0.001)$. It further highlighted that Asian patients were less likely to attain stringent LDL cholesterol target (14.6\%) compared with European counterparts $(32.9 \%)$ [17]. The SURF study revealed an inadequate control of cardiovascular risk factors (particularly smoking, obesity), insufficient achievement of therapeutic targets, and underuse of drugs among the study population. In our study, none of the patients achieved the recommended LDL-C $<70 \mathrm{mg} / \mathrm{dL}$. The poor control of LDL-C in our population is a matter of concern, highlighting gaps in prescribing adequate statin therapy, especially for the high-risk category. The SURF study elucidated that the poor control of lipids in Asia might be attributed to professional attitudes, patient preferences, ineffective implementation of guidelines, poor access to cardiac rehabilitation, and/or lack of professional guidelines 
[17].

Only around a quarter of the patients in our study received adequate high-intensity statin therapy, reflecting lacuna in dose titration and clinical inertia of physicians while prescribing statin therapy. A retrospective cohort analysis found a graded association between intensity of statin therapy and mortality; patients treated with maximal doses of highintensity statins had lower mortality compared with those receiving submaximal doses [18]. Barriers to guideline implementation for physicians might include complexity of guidelines, lack of training in CVD prevention, and time constraints [19]. Additionally, patient preferences, perceived side effects, and cost-effectiveness of maintaining optimal lipid levels might also influence the physician's decision for prescribing suboptimal statin therapy [20,21]. Evidence from a study in Singapore revealed that reduction in LDL-C by statins was not influenced by Asian ethnicity or BMI, and recommended upward titration of statin dosages when target lipid levels are not achieved [22].

The DYSIS study highlighted that use of non-statins was lowest for Indian patients; majority $(95.8 \%)$ were treated with statin monotherapy [14]. The 2018 ACC/AHA guidelines recommended addition of ezetimibe to maximally tolerated statin therapy when LDL-C level remains $\geq 70$ $\mathrm{mg} / \mathrm{dL}$ in very-high-risk patients (history of multiple major ASCVD events or 1 major ASCVD event and multiple highrisk conditions). The guidelines also suggested adding ezetimibe and consequently a PCSK9 inhibitor in patients with severe hypercholesterolemia if LDL-C levels remain $\geq 100 \mathrm{mg} / \mathrm{dL}$, after considering the long-term safety and costeffectiveness [7]. A physician survey across India illustrated that only $52.4 \%$ doctors prescribed ezetimibe, despite its well-established effectiveness for reducing major cardiovascular events in combination with statins [23, 24]. The International ChoLesterol management Practice Study (ICLPS), a retrospective study including India, reported that $32.1 \%$ of very high-risk and $51.9 \%$ of high-risk patients achieved LDL-C goals through combination therapies such as statin, statin plus fibrate, and statin plus cholesterol absorption inhibitor [25]. A retrospective study from Japan reported high goal attainment rates of LDL-C $<100 \mathrm{mg} / \mathrm{dL}$ among $52.6 \%$ patients in primary and $69.9 \%$ in secondary prevention cohort. The study emphasized that high compliance rate of patients to appropriate therapy could have contributed to the relatively higher LDL-C control levels [26].

Our study results found that a substantial proportion of individuals without ASCVD had a high prevalence of CVD risk factors such as obesity and prehypertension. In our attempt to minimize the cumulative lifetime exposure to atherogenic lipoproteins, experts recommend primordial and primary prevention strategies designed to lower lipid levels closer to optimal levels be initiated at an early age wherein such strategies would have the most impact. For instance, Ference, et al, argue that although the short-term risk of a CVD event is low during young adulthood and middle age, the risk of experiencing a CVD event increases log-linearly when the overall cumulative LDL threshold exceeds 5000 mg-years; thereby a decrease in LDL-C by $1 \mathrm{mmol} / \mathrm{L}$ at age 25 years should reduce the lifetime risk of CVD events by $50 \%$, resulting in a $23 \%$ absolute risk reduction. [19]. It is imperative to adopt a focused and individualized approach to monitor and manage the 7 metrics of cardiovascular health, including cigarette smoking, obesity, hypertension, high cholesterol, physical inactivity, poor diet, and diabetes. Ference et al recommended that alongside lifestyle modifications, the addition of lipid-lowering therapy should begin early in adulthood for individuals with a high-inherited burden of LDL (patients with familial hypercholesterolemia) or patients with higher than optimal lipid levels [19].

Diabetes doubles the risk for CVD, independent of other conventional risk factors. Diabetes develops at a lower lean body mass and at earlier age among the Indian population. In our study, among individuals with comorbid ASCVD and diabetes, only one-fifth attained the LDL-C thresholds of $<100 \mathrm{mg} / \mathrm{dL}$. An observational study from Germany showed that the proportion of individuals with diabetes who achieved target LDL-C $<100 \mathrm{mg} / \mathrm{dL}$ were lower than for the ASCVD cohort (18.5\% and 22.4\%) [15]. A real-world study involving 178 sites from India reported that among patients with diabetes and overt CVD, only $22.87 \%$ achieved LDL-C $<70$ $\mathrm{mg} / \mathrm{dL}$ [27]. In a physician survey, Wander et al highlighted that $50 \%$ doctors in India chose not to use a statin in persons with diabetes, irrespective of their LDL-C levels [23]. For individuals with diabetes having CVD, most guidelines recommend intensive statin therapy alongside lifestyle modifications, or a 10-year risk of a cardiovascular event [28]. Addition of non-statins such as ezetimibe can be beneficial for the high-risk statin-treated patients with diabetes. The ACCORD-lipid trial suggested that addition of fenofibrate therapy may reduce CVD events in diabetic patients with hypertriglyceridemia and low HDL-C [28-30]. Evidence from multiple studies have evaluated the potential effect of PCSK9 inhibitors, bile acid sequestrants, niacin, omega-3-fatty acids as add-on therapies to statins for patients with diabetes [29, 30]. However, the incremental benefit of these drugs in patients with diabetes and comorbid ASCVD needs to be explored further.

Majority of our very-high risk patients with comorbid ASCVD and T2DM had LDL-C level $\geq 100 \mathrm{mg} / \mathrm{dL}$, despite receiving moderate- or high-intensity statin therapy. These results are in alignment with a retrospective study from Italy, which showed relatively poor control rates of LDL-C in high or very high European SCORE risk individuals. Multivariate analysis in this study revealed that high-risk SCORE estimation was a strong and independent predictor for lack of achieving the predefined therapeutic targets of LDL-C [31]. Therapeutic inertia, gaps in disease monitoring, patient resistance to lifestyle measures and poor drug adherence in high-risk patients might be attributable for the elevated LDLC levels. Data from TECOS, a clinical trial among patients with T2DM and established ASCVD, also demonstrated that although most high-risk patients with T2DM and cardiovascular disease were on lipid-lowering therapy, only one-third had LDL-C $<70 \mathrm{mg} / \mathrm{dL}$ [32]. 
Our study is one of the largest real-world studies evaluating the LDL goal attainment in patients receiving statin therapy in India. However, the retrospective nature of the study was a limitation to ascertain the causal association between statin therapy and LDL-C levels. Data on ASCVD risk score, familial hypercholesterolemia, adverse effects of statin therapy, and other lipid-lowering strategies such as ezetimibe, fibrates or non-statins were not available. Segregated data on patients with CHD and non-coronary forms of atherosclerotic disease were not available. The study did not evaluate if statin intolerance, patient adherence, or cost-effectiveness affected the therapeutic decisions of doctors for prescribing statin therapy. Additionally, the study included patients only from the private sector, wherein the cost of the medication is primarily out-of-pocket expenditure by the patients. A significant proportion of the Indian population avails healthcare from public or government facilities, where the common lipid reducing medication such as statins are dispensed free of cost. Hence, the results may not be generalizable to the entire population in the country. The recent guidelines by the EAS/ESC recommend much lower LDL-C targets considering factors such as comorbid chronic kidney diseases (CKDs). However, the updated NCEP ATP guideline was used to determine the LDL-C goals in our study because of unavailability of data on CKD and the ambiguous validity of other guidelines for the Indian population.

\section{Conclusion}

This study presented real-world insights from a large subset of Indian population and demonstrated that levels of LDL-C that were higher than guideline recommended targets, especially among ASCVD patients, despite receiving statin therapy. The LDL control is a cause of concern, as majority of the patients remain at high-risk for poor CVD outcomes. There are pitfalls in the real-world management of prescribing statin therapy for primary and secondary prevention of ASCVD. It is imperative to formulate specific approaches that enhance concordance to guideline recommended statin therapy, including timely dose titration and use of alternative therapy for optimal management of dyslipidemia and CVD in the Indian subcontinent. The addition of non-statins can further provide a window of opportunity for the optimal control of LDL-C levels among the high-risk population in India.

\section{Acknowledgements}

The authors thank all the physicians and doctors across India who kindly agreed to participate in the LIPIMAP study and extended their support for data collection. The authors thank Piyalee Pal, Covance, for providing medical writing support for development of the manuscript. The authors also thank Garima Joshi Sciformix, Covance for providing statistical support.

\section{References}

[1] World Health Organization. Cardiovascular diseases factsheet, 2017. Cited 13 Oct 2019. Available from https://www.who.int/health-topics/cardiovascular-diseases [updated 2019/10/13/17:22:53].

[2] Jagannathan R, Patel SA, Ali MK, Narayan KMV. Global Updates on Cardiovascular Disease Mortality Trends and Attribution of Traditional Risk Factors. Curr Diab Rep. 2019; 19 (7): 44.

[3] Institute for Health Metrics and Evaluation. Age standardized death rate cardiovascular diseases India, Global burden of disease, 2017. cited 13 Oct 2019. Available from http://www.healthdata.org/india.

[4] Gupta R, Rao RS, Misra A, Sharma SK. Recent trends in epidemiology of dyslipidemias in India. Indian Heart J. 2017; 69 (3): 382-92.

[5] Joshi SR. Prevalence of Dyslipidemia in Urban and Rural India: The ICMR-INDIAB Study. Plos One. 2014; 9 (5): e96808.

[6] Silverman MG, Ference BA, Im K, Wiviott SD, Giugliano RP, Grundy SM, et al. Association Between Lowering LDL-C and Cardiovascular Risk Reduction Among Different Therapeutic Interventions: A Systematic Review and Meta-analysis. JAMA 2016; 316 (12): 1289-97.

[7] Grundy SM, Stone NJ, Bailey AL, Beam C, Birtcher KK, $\begin{array}{llll}\text { Blumenthal RS, } & \text { et } & \text { al. } & 2018\end{array}$ AHA/ACC/AACVPR/AAPA/ABC/ACPM/ADA/AGS/APhA/ ASPC/NLA/PCNA guideline on the management of blood cholesterol: a report of the American College of Cardiology/American Heart Association Task Force on Clinical Practice Guidelines. J Am Coll Cardiol. 2019 Jun 17; 73 (24): e285-350. Available from: https://ahajournals.org/doi/10.1161/CIR.0000000000000625.

[8] Catapano AL, Graham I, De Backer G, et al. ESC/EAS guidelines for the management of dyslipidaemias. European heart journal. 2016 28; 37 (39): 2999-3058. Available from: https://academic.oup.com/eurheartj/article/37/39/2999/241499 5.

[9] Jellinger PS, Handelsman Y, Rosenblit PD, et al. American Association of Clinical Endocrinologists and American College of Endocrinology guidelines for the management of dyslipidemia and prevention of cardiovascular disease. Endocr Pract. 2017; 23: 1-87 [updated 2019/10/13/17:47:00].

[10] Grundy SM CJ, Merz CN, Brewer HB, Clark LT, Hunninghake DB, et al. A summary of implications of recent clinical trials for the National Cholesterol Education Program Adult Treatment Panel III guidelines. Arterioscler Thromb Vasc Biol. 2004 Aug 1; 24 (8): 1329-30.

[11] Cholesterol Treatment Trialists' (CTT) Collaboration, Baigent $\mathrm{C}$, Blackwell L, et al. Efficacy and safety of more intensive lowering of LDL cholesterol: a meta-analysis of data from 170,000 participants in 26 randomised trials. Lancet. 2010; 376: $1670-81$.

[12] Collins R, Reith C, Emberson J, et al. Interpretation of the evidence for the efficacy and safety of statin therapy. Lancet. 2016; 388: 2532-61. 
[13] Park JE, Chiang C-E, Munawar M, Pham GK, Sukonthasarn A, Aquino AR, et al. Lipid-lowering treatment in hypercholesterolaemic patients: the CEPHEUS Pan-Asian survey. Eur J Prev Cardiol. 2012; 19 (4): 781-94.

[14] Poh K-K, Ambegaonkar B, Baxter CA, et al. Low-density lipoprotein cholesterol target attainment in patients with stable or acute coronary heart disease in the Asia-Pacific region: results from the Dyslipidemia International Study II. Eur $J$ Prev Cardiol. 2018; 25 (18): 1950-63.

[15] März W, Dippel F-W, Theobald K, Gorcyca K, Iorga ŞR, Ansell D. Utilization of lipid-modifying therapy and lowdensity lipoprotein cholesterol goal attainment in patients at high and very-high cardiovascular risk: Real-world evidence from Germany. Atherosclerosis. 2018; 268: 99-107.

[16] Malhotra N, Keshan MK, Agarwal A, et al. DemographIc Assessment and EValuation of DEgree of Lipid Control in High Risk Indian DySlipidemia PatiEnts (DIVERSE Study). $J$ Assoc Physicians India. 2016; 64 (4): 38-46.

[17] Zhao M, Cooney MT, Klipstein-Grobusch K, et al. Simplifying the audit of risk factor recording and control: A report from an international study in 11 countries. Eur J Prev Cardiol. 2016; 23 (11): 1202-10.

[18] Rodriguez F MD, Knowles JW, Virani SS, Lin S, Heidenreich PA. Association between intensity of statin therapy and mortality in patients with atherosclerotic cardiovascular disease. JAMA cardiology. 2017 Jan 1; 2 (1): 47-54.

[19] Ference BA, Graham I, Tokgozoglu L, Catapano AL. Impact of Lipids on Cardiovascular Health: JACC Health Promotion Series. J Am Coll Cardiol. 2018; 72 (10): 1141-56.

[20] Graham IM, Stewart M, Hertog MGL. Factors impeding the implementation of cardiovascular prevention guidelines: findings from a survey conducted by the European Society of Cardiology. European Journal of Cardiovascular Prevention \& Rehabilitation. 2006; 13 (5): 839-45.

[21] Setia S, Fung SS-W, Waters DD. Doctors' knowledge, attitudes, and compliance with 2013 ACC/AHA guidelines for prevention of atherosclerotic cardiovascular disease in Singapore. Vasc Health Risk Manag. 2015; 11: 303-10.

[22] Tan CE, Loh LM, Tai ES. Do Singapore patients require lower doses of statins? The SGH Lipid Clinic experience. Singapore Med J. 2003; 44 (12): 635-8.

[23] Wander GS, Jadhav UM, Chemburkar A, Lopez M, Gogtay J. Lipid management in India: a nationwide, cross-sectional physician survey. Lipids Health Dis 2017; 16 (1): 130.

[24] Vavlukis M, Vavlukis A. Adding ezetimibe to statin therapy: latest evidence and clinical implications. Drugs in Context. 2018; 7: 212534.

[25] Danchin N, Almahmeed W, Al-Rasadi K, et al. Achievement of low-density lipoprotein cholesterol goals in 18 countries outside Western Europe: The International ChoLesterol management Practice Study (ICLPS). European journal of preventive cardiology. 2018 Jul; 25 (10): 1087-94 [updated 2019/10/13/18:08:38].

[26] Umeda T, Hayashi A, Harada A, et al. Low-density lipoprotein cholesterol goal attainment rates by initial statin monotherapy among patients with dyslipidemia and high cardiovascular risk in Japan- A Retrospective Database Analysis. Circ J. 2018; 82 (6): 1605-13.

[27] Mithal A, Majhi D, Shunmugavelu M, Talwarkar PG, Vasnawala H, Raza AS. Prevalence of dyslipidemia in adult Indian diabetic patients: A cross sectional study (SOLID). Indian J Endocrinol Metab. 2014; 18 (5): 642-7.

[28] Lazarte J, Hegele RA. Dyslipidemia management in adults with diabetes. Can J Diabetes. 2019 Jul 12. pii: S1499-2671 (19) 30373-9.

[29] Feingold KR, Grunfeld C. Diabetes and Dyslipidemia. In: Feingold KR, Anawalt B, Boyce A, Chrousos G, Dungan K, Grossman A, et al., editors. Endotext. South Dartmouth (MA): MDText.com, Inc.; 2000. Cited 22 Oct 2019. Available from https://www.ncbi.nlm.nih.gov/books/NBK305900/

[30] Rodriguez V NJ, Schwartzbard AZ. Towards more specific treatment for diabetic dyslipidemia. Curr Opin Lipidol. 2018 Aug; 29 (4): 307.

[31] Presta V, Figliuzzi I, Miceli F, Coluccia R, Fogacci F, Cicero AF, Ferrucci A, Borghi C, Volpe M, Tocci G, Guida P. Achievement of low density lipoprotein (LDL) cholesterol targets in primary and secondary prevention: Analysis of a large real practice database in Italy. Atherosclerosis. 2019 Jun; 285: $40-8$

[32] De Ferrari GM, Stevens SR, Ambrosio G, Leonardi S, Armstrong PW, Green JB, Wamil M, Holman RR, Peterson ED, TECOS Study Group. Low-density lipoprotein cholesterol treatment and outcomes in patients with type 2 diabetes and established cardiovascular disease: Insights from TECOS. Am Heart J. 2020 Feb; 220: 82-8.

[33] American Diabetes Association. Pharmacologic approaches to glycemic treatment: Standards of Medical Care in Diabetes2018. Diabetes care. 2018 Jan; 41 (Suppl 1): S73.

[34] Misra. Consensus Statement for Diagnosis of Obesity, Abdominal Obesity and the Metabolic Syndrome for Asian Indians and Recommendations for Physical Activity, Medical and Surgical Management. JAPI. 2009; 57 (2): 163-70.

[35] Chobanian AV, Bakris GL, Black HR, Cushman WC, Green LA, Joseph L. Izzo, Jr., et al. The Seventh Report of the Joint National Committee on Prevention, Detection, Evaluation, and Treatment of High Blood Pressure: The JNC 7 Report. JAMA. 2003; 289 (19): 2560-71. 